\title{
Sleep disordered breathing in patients receiving therapy with buprenorphine/ naloxone
}

\author{
Robert J. Farney ${ }^{1}$, Amanda M. McDonald ${ }^{1}$, Kathleen M. Boyle'1, Gregory L. Snow², \\ R.T. Nuttall ${ }^{1}$, Michael F. Coudreaut ${ }^{3}$, Theodore J. Wander ${ }^{3}$ and James M. Walker ${ }^{1}$
}

Affiliations: ${ }^{1}$ Intermountain Sleep Disorders Center, LDS Hospital, Salt Lake City, UT, ${ }^{2}$ Statistical Data Center, LDS Hospital, Salt Lake City, UT, and ${ }^{3}$ Psychiatry Dept, LDS Hospital, Salt Lake City, UT, USA.

Correspondence: R.J. Farney, Intermountain Sleep Disorders Center, LDS Hospital, 325 8th Ave and C Street, Salt Lake City, UT 84143, USA. E-mail: rjfmdamsn.com

ABSTRACT Patients using chronic opioids are at risk for exceptionally complex and potentially lethal disorders of breathing during sleep, including central and obstructive apnoeas, hypopnoeas, ataxic breathing and nonapnoeic hypoxaemia. Buprenorphine, a partial $\mu$-opioid agonist with limited respiratory toxicity, is widely used for the treatment of opioid dependency and chronic nonmalignant pain. However, its potential for causing sleep disordered breathing has not been studied.

70 consecutive patients admitted for therapy with buprenorphine/naloxone were routinely evaluated with sleep medicine consultation and attended polysomnography.

The majority of patients were young (mean \pm SD age $31.8 \pm 12.3$ years), nonobese (mean \pm SD body mass index $24.9 \pm 5.9 \mathrm{~kg} \cdot \mathrm{m}^{-2}$ ) and female $(60 \%)$. Based upon the apnoea/hypopnoea index (AHI), at least mild sleep disordered breathing (AHI $\geqslant 5$ events $\cdot \mathrm{h}^{-1}$ ) was present in $63 \%$ of the group. Moderate (AHI $\geqslant 15-$ $<30$ events $\left.\cdot \mathrm{h}^{-1}\right)$ and severe $\left(\mathrm{AHI} \geqslant 30\right.$ events $\cdot \mathrm{h}^{-1}$ ) sleep apnoea was present in $16 \%$ and $17 \%$, respectively. Hypoxaemia, defined as an arterial oxygen saturation measured by pulse oximetry, of $<90 \%$ for $\geqslant 10 \%$ of sleep time, was present in $27(38.6 \%)$ patients.

Despite the putative protective ceiling effect regarding ventilatory suppression observed during wakefulness, buprenorphine may induce significant alterations of breathing during sleep at routine therapeutic doses.

@ERSpublications

Buprenorphine at routine therapeutic doses may induce significant alterations of breathing during sleep http://ow.ly/kMIQg

For editorial comments see page 297.

Received: Aug 022012 | Accepted after revision: Sept 212012 | First published online: Oct 252012

Conflict of interest: Disclosures can be found alongside the online version of this article at www.erj.ersjournals.com 


\section{Introduction}

Patients using chronic opioids are at risk for exceptionally complex and potentially lethal disorders of breathing during sleep, including central and obstructive apnoeas, hypopnoeas, ataxic breathing and nonapnoeic hypoxaemia [1-5]. The mortality rates associated with the use of nonillicit opioids have increased in parallel with the unprecedented escalation of opioid prescriptions since 1997 [6-9].

Buprenorphine is a semisynthetic opioid partial $\mu$-agonist that has become widely used for the therapy of opioid dependency since it was patented in 1969 and was approved for marketing in the USA in 1981. The retail distribution of buprenorphine in the USA (2002-2008) has increased from 107 to $800317 \mathrm{~g}$ ( $\sim 7000$ fold) [10]. An important underlying factor driving the increasing prescription rate for this drug is the perceived wider safety profile regarding respiratory suppression compared to other full $\mu$-agonists such as methadone [11-15]. Based upon the most extensive worldwide experience in France, where general practitioners have been permitted to prescribe buprenorphine since 1996, the estimated yearly death rate (1994-1998) for methadone was at least threefold greater than the death rate related to buprenorphine $[16,17]$. Although the death rate associated with methadone in the USA (2001-2006) has increased by $272 \%$, the death rate for buprenorphine has not been specifically tracked [10]. In October 2002, the United States Food and Drug Administration approved buprenorphine monotherapy (Subutex) and a combination product of buprenorphine/naloxone (Suboxone) for opioid detoxification therapy. Subutex and Suboxone are the first narcotic medications available for the treatment of opioid dependence that can be prescribed in a primary care office setting in the USA under the Drug Addiction Treatment Act of 2000 (Public Law 106-310) [18].

Despite the well-known respiratory effects of $\mu$-opioid agonists during sleep, we are unaware of any investigations of buprenorphine while subjects are sleeping except for a single case report in which buprenorphine was implicated as a cause of central sleep apnoea [19]. Based upon our anecdotal experience, the true prevalence of sleep disordered breathing (SDB) and sleep-related hypoxaemia associated with buprenorphine is likely to be substantial. However, in contrast to obstructive sleep apnoea syndrome, there are presently no guidelines or standards regarding indications for performing polysomnography in patients who use opioids. Due to the potential lethality of chronic opioids and the lack of any specific risk factors that could be used to predict those who may have central sleep apnoea, we implemented a care process model in which comprehensive polysomnography is a standard component of our inpatient opioid detoxification programme when using buprenorphine (Suboxone or Subutex).

The purpose of this report is threefold: 1) to summarise the organisation of our care process model; 2) to characterise the prevalence, severity and types of SDB in hospitalised patients receiving buprenorphine for detoxification from opioids; and 3) to identify potential risk factors that might be used in the future to select patients for testing.

\section{Methods}

\section{Patient selection}

From November 2010 until August 2011, every patient admitted to an adult facility at the LDS Hospital (Day Spring) in Salt Lake City (UT, USA) (elevation $1500 \mathrm{~m}$ ) for detoxification from opioid dependency using buprenorphine was eligible regardless of symptoms. The only limitation was availability of laboratory space or technical staff.

\section{Care process model}

In accordance with current practices, the induction phase of buprenorphine (Suboxone or Subutex) administration began once the patient had abstained from using opioids for 12-24 h and was in the early stage of withdrawal $[13,18,20]$. During the subsequent stabilisation phase, at which time withdrawal symptoms had abated, a focused history and physical examination were obtained. The potential risks associated with chronic opioid therapy, the rationale for documenting the presence of SDB and possible subsequent respiratory therapy were discussed with the patient. Prior to beginning the maintenance phase and discharge, comprehensive monitored polysomnography was performed, either in the sleep laboratory or on the psychiatry floor using wireless technology [21]. Therapy with positive airway pressure (usually adaptive servoventilation) and/or supplemental oxygen was provided according to current practices.

\section{Polysomnography studies}

Standard attended 19-channel polysomnography (Cadwell Laboratories Inc., Kennewick, WA, USA) was performed and manually scored according to criteria established by the American Academy of Sleep Medicine [22]. Parameters consisted of frontal, central and occipital electroencephalogram, right and left electro-oculogram, and submentalis electromyogram. Airflow was detected by nasal pressure transducers 
(PTAF II; Pro-Tech Services Inc., Mukilteo, WA, USA) recorded in the direct current mode (no filtering) and by oral-nasal thermistors (Thermisense 5700B; Salter Labs, Arvin, CA, USA). Respiratory effort was determined by measurement of chest and abdomen motion with respiratory inductive plethysmography transducers which included a qualitative sum channel. Arterial oxygen saturation $\left(\mathrm{SpO}_{2}\right)$ was measured by the Cadwell oximeter (Cadwell Laboratories Inc.) with a four-beat averaging mode. Apnoeas were scored on the basis of absence of thermistor airflow for $\geqslant 10 \mathrm{~s}$. Obstructive apnoeas were defined by the presence of respiratory effort; central apnoeas by the absence of respiratory effort. Hypopnoeas were defined as a $\geqslant 50 \%$ reduction in airflow for $\geqslant 10 \mathrm{~s}$ associated with $\geqslant 3 \%$ decrease in $\mathrm{SpO}_{2}$ or terminating electroencephalogram arousal. Hypopnoeas were not differentiated as obstructive or central. Apnoea/hypopnoea index (AHI), obstructive apnoea index (OAI), central apnoea index (CAI) and hypopnoea index (HI) were computed as the total of defined respiratory events divided by the total sleep time in hours. Each record was scored simultaneously by two authors (R.J. Farney and J.M. Walker) for Biot's respiration or ataxic breathing according to previously published criteria [23] (fig. 1). Oximetry data were analysed for mean $\mathrm{SpO}_{2}$, lowest $\mathrm{SpO}_{2}$ and time spent $<90 \% \mathrm{SpO}_{2}$ during sleep. In six patients who required supplemental oxygen due to severe hypoxaemia that developed during polysomnography, only the initial room air portions of studies were used for computing respiratory statistics.

\section{Statistical analysis}

Descriptive statistics consisting of mean, standard deviation and ranges were derived for each sleep and respiratory measure. A random forest model was fit with AHI as the response variable and the buprenorphine dose, individual STOP-Bang indicators (snoring, tiredness, obstruction (witnessed apnoeas), pressure (hypertension), body mass index (BMI $>35 \mathrm{~kg} \cdot \mathrm{m}^{-2}$ ), age (>50 years), neck circumference (>15.75 inches) and gender (male)), use of benzodiazepines, antidepressants, antipsychotics and smoking history as the predictor variables. A random forest is a machine learning tool that models the response using many "trees" which are built using binary splits of the predictor variables [24-26]. A random forest will find nonlinear and interaction relationships between the response and the predictors. This model was used as a first step to exploring possible relationships with the predictor variables. Separate random forests were fit with the same predictors but with AHI, CAI, OAI, HI, ataxic breathing, mean $\mathrm{SpO}_{2}$, lowest $\mathrm{SpO}_{2}$ and percentage of total sleep time at $<90 \% \mathrm{SpO}_{2}$ as response variables. The relationship between the response variables and the individual predictors were also explored graphically. The KolmogorovSmirnov test was used to compare the two groups of outcomes, with the group membership being determined by benzodiazepines, antipsychotics, antidepressants and cigarette smoking history (32 tests in total) $[27,28]$.

\section{Results}

\section{Study population}

The characteristics of the study subjects are shown in table 1. Typical risk factors for obstructive sleep apnoea (OSA) were generally not found. The majority of patients were young (mean $\pm S D$ age $31.8 \pm 12.3$ years), nonobese (mean \pm SD BMI $24.9 \pm 5.9 \mathrm{~kg} \cdot \mathrm{m}^{-2}$ ) and female $(60 \%)$. The STOP-Bang

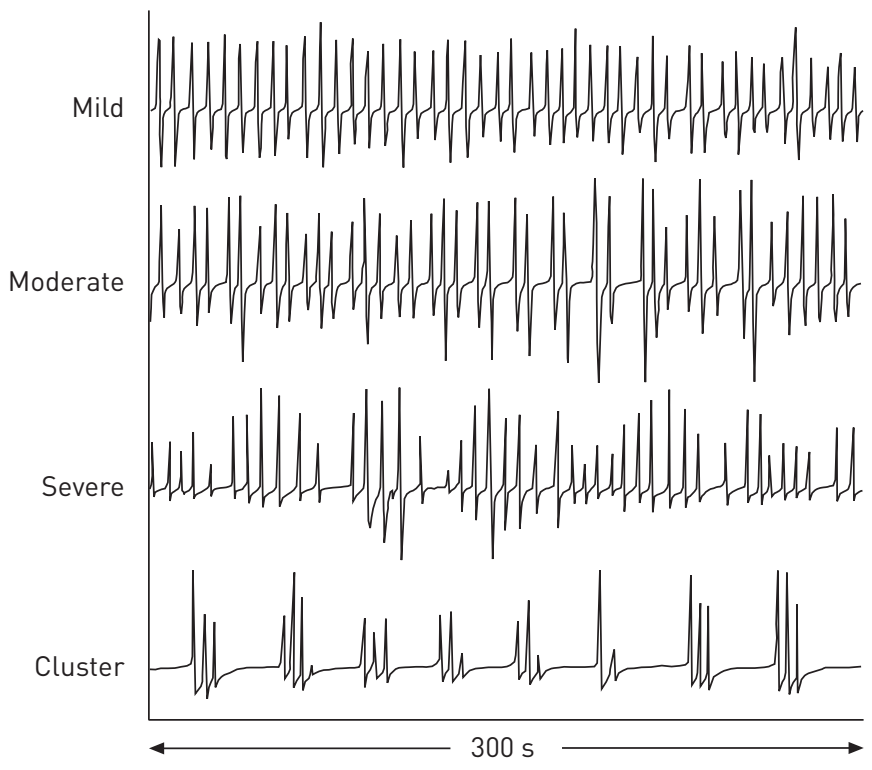

FIGURE 1 Variations of Biot's breathing patterns or ataxic respiration. Airflow patterns obtained from pressure transducer airflow signals (air pressure) showing varying degrees of ataxic or irregular breathing (mild, moderate and severe) plus an example of "cluster breathing" obtained from patients who were chronically receiving opioid medications. Reproduced from [23] with permission from the publisher. 
TABLE 1 Demographics and possible risk factors for sleep disordered breathing

\begin{tabular}{lccc} 
& Males & Females & All \\
\hline Subjects & 28 & 42 & 70 \\
Age years & $28.5 \pm 9.3(18-53)$ & $34.1 \pm 13.6(19-73)$ & $31.8 \pm 12.3(18-73)$ \\
BMI kg $\mathbf{m}^{-2}$ & $24.4 \pm 4.7(15.3-37.9)$ & $25.1 \pm 6.6(16.2-41.0)$ & $24.9 \pm 5.9(15.3-41.0)$ \\
Mallampati score 1-4 & $2.9 \pm 0.7(2.0-4.0)$ & $2.6 \pm 0.8(1.0-4.0)$ & $2.7 \pm 0.7(1.0-4.0)$ \\
STOP-Bang score 0-8 & $3.2 \pm 1.1(1.0-6.0)$ & $2.3 \pm 1.2(0.0-6.0)$ & $2.7 \pm 1.2(0.0-6.0)$ \\
Buprenorphine & & & \\
$\quad$ Total dose mg & $21.5 \pm 17.5(2.0-76.0)$ & $16.5 \pm 10.7(2.0-48.0)$ & $18.5 \pm 13.0(2.0-76.0)$ \\
Dosage $\mathrm{mg} \cdot \mathrm{h}^{-1}$ & $0.4 \pm 0.2(0.1-1.1)$ & $0.4 \pm 0.2(0.1-1.1)$ & $0.4 \pm 0.2(0.1-1.1)$ \\
& & &
\end{tabular}

Data are presented as $\mathrm{n}$ or mean \pm SD (range). BMI: body mass index; STOP-Bang: snore, tiredness, obstruction (witnessed apnoea), pressure (hypertension), BMI $\left(>35 \mathrm{~kg} \cdot \mathrm{m}^{-2}\right.$ ), age $(>50)$ neck circumference $>15.75$ inches, gender (male).

questionnaire, previously validated for screening pre-surgical patients for OSA, incorporates symptoms (snoring, tiredness, witnessed apnoeas and hypertension) with demographics (BMI, age, neck size and sex) [8]. A score $\geqslant 3$ indicates a high probability of AHI $>5$ events $\cdot h^{-1}$ (sensitivity $83.6 \%$ ). Higher scores are correlated with more severe sleep apnoea [29]. The mean \pm SD STOP-Bang score measured 2.7 \pm 1.2 . A Mallampati score of 3 or 4 indicates the presence of a relatively small pharyngeal lumen, obstructive in appearance, which may predispose to sleep disordered breathing, but the classification does not predict severity [30]. The Mallampati score in this population measured a mean \pm SD $2.7 \pm 0.7$ (median 3 ).

\section{Sleep measures}

The results of sleep measurements are shown in table 2. These data reflect the entire sleep record, with and without supplemental oxygen (six and 64 patients, respectively). Mean total sleep time was somewhat reduced, at $5.5 \mathrm{~h}$. The rapid eye movement (REM) time as a percentage of total sleep time (mean $\pm \mathrm{SD}$ ) measured $5.3 \pm 6.7 \%$. We have observed that some patients using opioids chronically present with strikingly unusual sleep patterns, characterised by sustained N2 non-REM sleep, being almost devoid of any awakenings with minimal-to-absent REM sleep (fig. 2).

\section{Respiratory measures}

The results of standard respiratory parameters are shown in table 3. Various manifestations of SDB were common (i.e. apnoeas/hypopnoeas, hypoxaemia and ataxic breathing rhythm). At least mild sleep disordered breathing (AHI $\geqslant 5$ events $\cdot \mathrm{h}^{-1}$ ) was present in $63 \%$ of the group, consistent with previous reports of patients receiving chronic opioid therapy $[2,4]$. Moderate $\left(\right.$ AHI $\geqslant 15-<30$ events $\left.\cdot h^{-1}\right)$ and severe sleep apnoea $\left(\mathrm{AHI} \geqslant 30\right.$ events $\cdot \mathrm{h}^{-1}$ ) were present in $16 \%$ and $17 \%$ of patients, respectively. Mean overall AHI was 20.4 events $\cdot \mathrm{h}^{-1}$, with central apnoeas predominating (CAI 11.4 events $\cdot \mathrm{h}^{-1}$ ) and relatively few obstructive apnoeas (OAI 2.3 events $\cdot \mathrm{h}^{-1}$ ). Central apnoeas were more frequent in females than males

\section{TABLE 2 Sleep measurements}

\begin{tabular}{lccc} 
& Males & Females & All \\
\hline Subjects & 28 & 42 & 70 \\
TST h & $5.6 \pm 1.2(2.5-7.3)$ & $5.4 \pm 1.2(1.9-7.7)$ & $5.5 \pm 1.2(1.9-7.7)$ \\
N1 \% TST & $12.7 \pm 16.1(2.0-35.0)$ & $9.0 \pm 7.6(1.0-86.0)$ & $10.4 \pm 11.8(1.0-86.0)$ \\
N2 \% TST & $78.3 \pm 16.4(45.0-98.0)$ & $78.3 \pm 12.8(14.0-95.0)$ & $75.7 \pm 14.6(14.0-98.0)$ \\
N3 \% TST & $8.8 \pm 10.1(0.0-39.0)$ & $8.5 \pm 11.7(0.0-44.0)$ & $8.6 \pm 11.0(0.0-44.0)$ \\
REM stage \% TST & $6.6 \pm 7.5(0.0-36.0)$ & $4.3 \pm 5.9(0.0-18.0)$ & $5.3 \pm 6.7(0.0-36.0)$
\end{tabular}

Data are presented as $\mathrm{n}$ or mean \pm SD (range). TST: total sleep time; N1: stage N1 of non-rapid eye movement (REM) sleep as a percentage of TST; N2: stage N2 of non-REM sleep as a percentage of TST; N3: stage N3 of non-REM sleep as a percentage of TST; REM stage: REM stage of sleep as a percentage of TST. 
a)

TST $5.7 \mathrm{~h}$
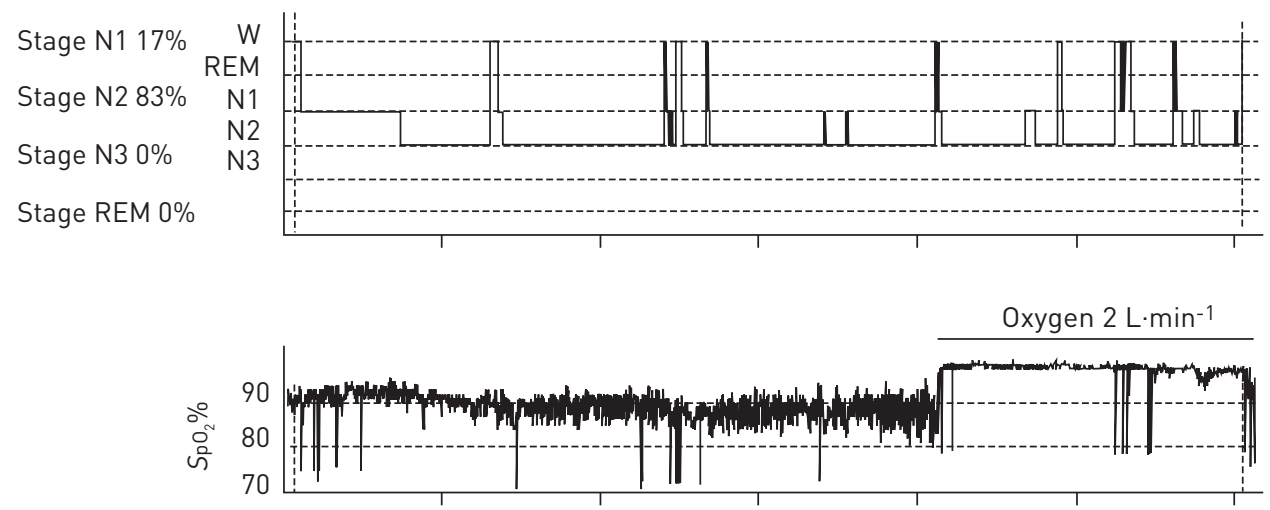

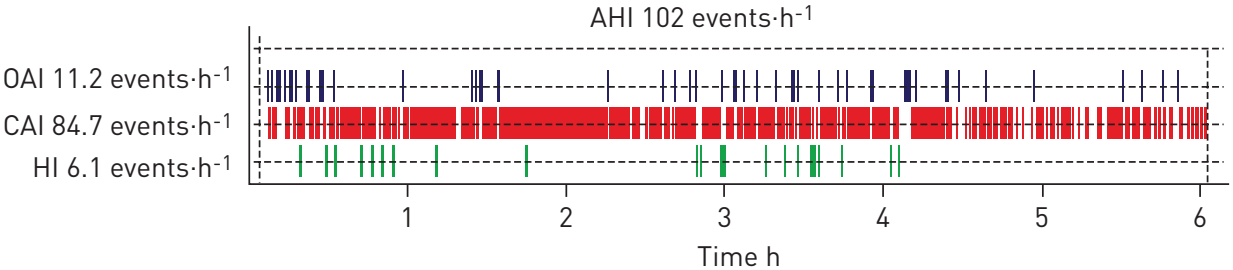

b)

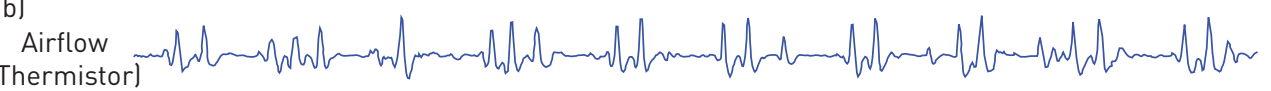

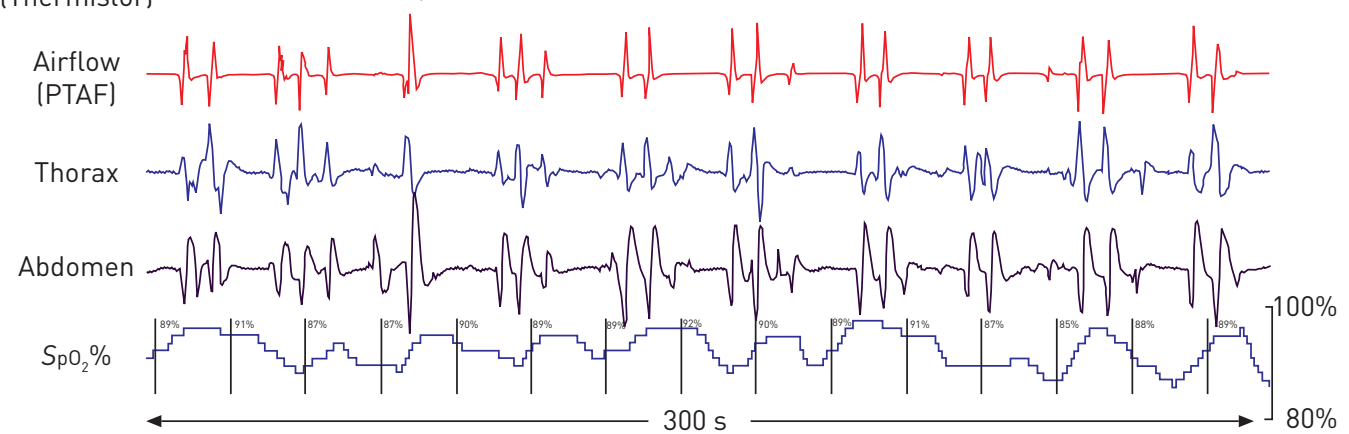

FIGURE 2 a) Sleep histogram and respiratory parameters from a patient with severe sleep disordered breathing. The patient was a 62-year-old female nonsmoker with history of snoring, tiredness, hypertension and with a body mass index of $20 \mathrm{~kg} \cdot \mathrm{m}^{-2}$ (STOP-Bang score 4). Polysomnography was performed $25 \mathrm{~h}$ after initiation of buprenorphine and having received a total dose of $6 \mathrm{mg}$. Medications included quetiapine, clorazepate, venlafaxine and omeprazole. Stages N1-N3 represent the length of each $\mathrm{N}$ stage of non-rapid eye movement (REM) sleep as a percentage of total sleep time (TST). Stage REM represents the length of REM stage of sleep as a per cent of TST. b) A representative 300-s sample of raw data characterised by a predominance of cluster breathing or Biot's respiration and recurrent hypoxaemia. Note the marked variability of underlying breathing pattern in terms of both rhythm and amplitude associated with oxygen desaturations. Arterial oxygen saturation $\left(\mathrm{SpO}_{2}\right)$ measured $<90 \%$ for $47.5 \%$ of sleep time, with a nadir of $80 \%$. W: patient awake; OAI: obstructive apnoea index; CAI: central apnoea index; HI: hypopnoea index; AHI: apnoea/hypopnoea index; PTAF: pressure transducer airflow; STOP-Bang: snore, tiredness, obstruction (witnessed apnoea), pressure (hypertension), BMI $\left(>35 \mathrm{~kg} \cdot \mathrm{m}^{-2}\right)$, age $(>50)$ neck circumference $>15.75$ inches, gender (male).

(mean CAI 14.9 events $\cdot \mathrm{h}^{-1}$ versus 6.3 events $\cdot \mathrm{h}^{-1}$, respectively). The prevalence of ataxic breathing for the group was $73 \%$, similar to our previous report in which $70 \%$ of subjects, mainly taking hydrocodone, oxycodone or methadone, were observed to have ataxic respiration [2]. In the present study group, moderate-to-severe ataxia was present in $20.0 \%$ and $18.6 \%$ respectively (38.6\% overall).

The mean $\mathrm{SpO}_{2}$ while breathing room air during the study was 91.7\% (normal for the study centre's elevation of $1500 \mathrm{~m}$ ). Hypoxaemia, defined as an $\mathrm{SpO}_{2}$ of $<90 \%$ for $\geqslant 10 \%$ of sleep time, was present in 27 $(38.6 \%)$ patients and the lowest measured $\mathrm{SpO}_{2}$ was $\leqslant 85 \%$ in $38(54.3 \%)$ patients. Of note, hypoxaemia was present in $13(28.2 \%)$ patients with $\mathrm{AHI} \leqslant 15$ events $\cdot \mathrm{h}^{-1}$. 


\begin{tabular}{lccr}
\multicolumn{1}{l}{ TABLE 3 Respiratory measurements } & \\
& Males & Females & All \\
\hline Subjects & 28 & 42 & 70 \\
AHI & $15.2 \pm 26.3(0.0-106.2)$ & $23.9 \pm 35.6(0.0-180.0)$ & $20.4 \pm 32.3(0.0-180.0)$ \\
CAI & $6.3 \pm 19.0(0.0-176.4)$ & $14.9 \pm 32.6(0.0-97.6)$ & $11.4 \pm 28.1(0.0-176.4)$ \\
OAI & $2.0 \pm 2.3(0.0-8.6)$ & $2.5 \pm 4.7(0.0-26.5)$ & $2.3 \pm 3.9(0.0-26.5)$ \\
HI & $6.9 \pm 4.8(0.0-71.8)$ & $6.5 \pm 9.6(0.0-42.6)$ & $6.6 \pm 11.8(0.0-71.8)$ \\
Baseline $\mathrm{SpO}_{2} \%$ & $92.7 \pm 3.0(86.0-98.0)$ & $91.0 \pm 3.5(83.0-98.0)$ & $91.7 \pm 3.4(83.0-98.0)$ \\
$\%$ of TST where $\mathrm{SpO}_{2}<\mathbf{9 0 \%}$ & $13.4 \pm 22.4(0.0-76.2)$ & $29.8 \pm 36.6(0.0-100.0)$ & $23.2 \pm 32.5(0.0-100.0)$
\end{tabular}

Data are presented as $\mathrm{n}$ or mean \pm SD (range). AHI: apnoea/hypopnoea index; CAl: central apnoea index; OAl: obstructive apnoea index; $\mathrm{HI}$ : hypopnoea index; $\mathrm{SpO}_{2}$ : arterial oxygen saturation measured by pulse oximetry; TST: total sleep time.

\section{Pharmacological data}

All but one patient was treated with combination buprenorphine/naloxone (Suboxone). One was treated with buprenorphine only (Subutex). The amount of buprenorphine received before polysomnography ranged from 2.0 to $76.0 \mathrm{mg}$ (mean \pm SD total dose $18.5 \pm 13.9 \mathrm{mg}$ ), with a target dose of $12-16 \mathrm{mg} \cdot \mathrm{day}^{-1}$. When standardised to $\mathrm{mg} \cdot \mathrm{h}^{-1}$ (total $\mathrm{mg}$ received/total hours including the first and last dose before polysomnography), the time-adjusted buprenorphine dose (mean $\pm \mathrm{SD}$ ) measured $0.4 \pm 0.2 \mathrm{mg} \cdot \mathrm{h}^{-1}$. Since all these patients were hospitalised, multiple drugs were commonly used, including benzodiazepines, neuroleptics and muscle relaxants. None of these medications had an additive effect. There were no significant differences in the groups in the frequency of apnoeas, hypopnoeas or measures of arterial oxygen saturation (fig. 3).

\section{Statistical analysis}

All of the random forest models showed little or no relationship between the predictor variables (e.g. BMI, sex and buprenorphine dose) and the response variables (i.e. apnoeas, hypopnoeas, ataxia and hypoxaemia). The best-fitting model was that predicting mean $\mathrm{SpO}_{2}$ and that model only reduced the variability (compared to an overall mean) by $19 \%$. This can be seen further in the graphical comparisons, where the distributions of the response variable are nearly identical between the groups determined by drug usage (see online supplementary material). Further analysis using Kolmogorov-Smirnov tests showed that the unadjusted p-values ranged from 0.01 to 0.99999 , with five being $<0.05$ (AHI by smoking history, mean
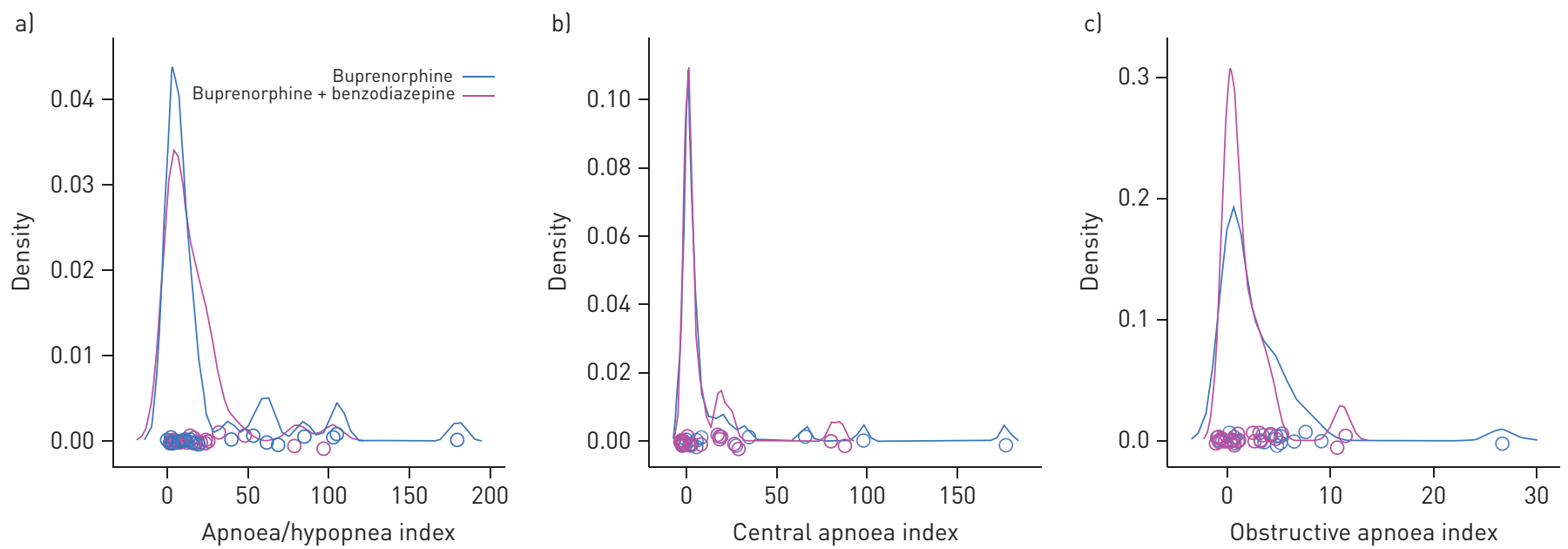

FIGURE 3 Probability distribution graphs showing kernel density estimates of a) apnoea/hypopnoea index, b) central apnoea index, and c) obstructive apnoea index separately for those receiving and not receiving benzodiazepines [31]. The overlap of the two curves within each subplot shows that there is no real practical difference in outcome between the two groups. Similar plots showed the same similarity with the other potential predictors on this group of subjects (see online supplementary material for all comparisons and correlations). 
$\mathrm{SpO}_{2}$ by smoking history, percentage of sleep $<90 \%$ by smoking history, AHI by antidepressants and CAI by antidepressants). However, when the p-values were adjusted for multiple comparisons using the false discovery rate method, the p-values then ranged from 0.22 to 0.99999 , indicating that none of the differences were statistically significant [32].

\section{Discussion}

The major findings from this study are: 1) clinically significant SDB occurred in many patients being initiated on buprenorphine/naloxone for opioid withdrawal therapy; 2) respiratory disturbances consisted predominantly of central apnoeas, ataxic breathing (Biot's respiration) and hypoxaemia, as seen with other opioids; 3 ) the presence and severity of breathing disturbances were not predicted by concomitant use of benzodiazepines or neuroleptics, buprenorphine dose or by standard risk factors for OSA; and 4) recognition of SDB in these patients was enabled by incorporating routine comprehensive polysomnography into our inpatient opioid detoxification protocol.

The discovery of SDB in patients receiving buprenorphine should not be surprising; however, it is widely regarded as a safe and effective opioid [11, 13, 33]. Furthermore, many clinicians may not be familiar with the unique pharmacologic profile of this particular opioid and its potential for respiratory toxicity [12, 20, $33,34]$. The biological effects of all commercially available narcotics are mediated through $\mu$-opioid receptors, with activation of classic G-protein coupled receptors that stimulate intracellular inhibitory pathways of both pain and respiratory neurons [35]. The molecular mechanisms responsible for opioid tolerance and the expression of less than maximum biological effects of partial agonists compared to full $\mu$ opioid agonists are complex, but polymorphism of the $\mu$-opioid-receptors and the recently discovered regulators of G-protein signalling may be involved [36, 37]. Genetic diversity of these mechanisms may underlie the individual variability seen clinically regarding expression of respiratory toxicity. In general, chronic opioid use reduces respiratory drive, destabilises pacemaker neurons that generate a regular breathing pattern during non-REM sleep, and simultaneously disables the normal protective arousal responses to hypoxaemia during sleep, with potentially fatal consequences [5].

Buprenorphine is a potent partial $\mu$-agonist (25-50 times greater than morphine) with very high receptor affinity (1000 times greater than morphine) and long dissociation half-life [12, 18]. Although it maintains an analgesic dose response across all levels, it appears to have a flat or U-shaped biological response on respiratory suppression, such that with increasing doses it has a lower maximum or ceiling effect. In both animal and human studies, for example, the ventilatory response to hypercapnia does not continually decrease with progressively greater doses, while the analgesic effect is maintained $[11,14,15,38-40]$. Consequently, it is regarded as a safer opioid compared to methadone. However, buprenorphine is still a highly potent opioid with potentially profound respiratory effects occurring below the ceiling level (i.e. at doses typically used for detoxification or for analgesia) [40]. Therefore, buprenorphine is capable of causing significant respiratory disturbances during sleep, like any other opioid. Furthermore, the respiratory toxicity of all opioids, but in particular buprenorphine, during sleep is underappreciated because existing studies focus on acute and not chronic administration; drugs are usually administered parenterally with measurements being performed during wakefulness; and the usual outcome measures are ventilatory responses to hypoxaemia or hypercapnia. The effects of opioids on respiratory pattern generation during sleep or the arousal responses to hypoxaemia and hypercapnia are not assessed.

There is a widely held view that respiratory depression resulting in fatal toxicity of buprenorphine is uncommon and when it occurs is linked with intravenous misuse and/or concomitant sedative drug ingestion, specifically benzodiazepines [10, 17, 41-43]. The putative mechanisms responsible for this interaction were recently reviewed by MÉGARBANE et al. [33]. $\gamma$-amino butyric acid (GABA) and opioid receptors are coexpressed in brainstem locations associated with respiratory control and utilise common intracellular transduction pathways. A pharmacokinetic interaction resulting in altered drug levels has also been postulated; however the exact mechanisms remain unclear. Consistent with our previous study [2], we did not find an increase in the AHI or measures of worse oxygenation when benzodiazepines or quetiapine were used within $24 \mathrm{~h}$ of polysomnography as compared to those taking buprenorphine alone. Nevertheless, the potential for adverse interactions with any GABA-ergic drugs, including alcohol, that are likely to be taken concomitantly must be considered as a serious risk for developing more severe adverse respiratory effects.

The respiratory effects of opioids were manifest in three semi-autonomous domains: fundamental breathing pattern (ataxia versus regular breathing rhythm), breathing interruptions (apnoeas and hypopnoeas) and gas exchange (hypoxaemia). The AHI is the most frequently reported outcome measure and defines the severity of sleep apnoea. However, the effect of opioid exposure in many subjects manifested as alteration of the basic breathing rhythm (i.e. ataxic or Biot's respiration), which may be very subtle and not necessarily 
associated with other definable respiratory events according to standard criteria. Hypoxaemia was found in numerous cases with relatively trivial evidence of SDB, as previously reported [44]. In this series, hypoxaemia was present in $38.6 \%$ of the total group and in $28.2 \%$ of those with AHI $<15$ events $\cdot h^{-1}$. It should be stressed that there was a wide range of individual susceptibility, with no clear predictive variables.

\section{Limitations of the study}

The presence of pre-existing underlying SDB unrelated to buprenorphine must be considered, but the possibility that this is an important factor seems unlikely. As we previously demonstrated in patients with high risk factors for OSA who were also receiving chronic opioid therapy compared to a matched control population not taking opioids, nonperiodic central apnoeas with unique ataxic breathing patterns were statistically more prevalent [2]. In the present study, the a priori risk for OSA was relatively low (mean STOP-Bang score 2.7), obstructive events were found in low frequency, the breathing patterns were most consistent with those previously associated with chronic opioid therapy and there were no other risk factors for central disturbances. It could be argued that SDB was related to residual effects of previous opioids; however, this seems highly unlikely since buprenorphine is only initiated during withdrawal states.

A second concern is that the respiratory events were influenced by other factors, such as concomitant medications, especially benzodiazepines. It is almost impossible to completely control for drug interactions in such a clinical population; however, we were unable to demonstrate a statistically significant effect of various confounding factors on any domain of SDB. In addition to the density plots, which gave a visual analysis, we were unable to demonstrate an interaction using quantitative statistics already discussed.

The present study was conducted at moderate elevation $(1500 \mathrm{~m})$. Therefore, these findings, especially the degree of hypoxaemia, may not apply to populations at lower elevations. The degree of breathing rhythm disturbances or the propensity for developing central apnoeas at lower elevations is also uncertain.

Finally, this was a short-term study with patients being studied generally within $48 \mathrm{~h}$ of initiation of buprenorphine. The presence and severity of adverse respiratory effects occurring months later while receiving maintenance therapy are unknown; however, based upon previous experiences with other opioids being used chronically, it is unlikely that the respiratory suppressant effects would resolve. We have no way of correlating the presence of respiratory abnormalities as described in this study with specific clinical outcomes or unexpected mortality. Evidence of an opioid effect could be seen in the majority of cases; however, the clinical significance of mild-to-moderate sleep apnoea, hypoxaemia or slight ataxic breathing is unknown without further studies.

\section{Clinical implications}

Standard symptoms, demographic factors and buprenorphine dose are poor predictors of significant adverse respiratory effects. Consequently, all patients receiving buprenorphine should probably be monitored at least initially using some type of objective study. Routine comprehensive polysomnography in all cases is impractical; however, limited cardiopulmonary sleep studies that incorporate $\mathrm{SpO}_{2}$ and respiratory pattern may be useful.

There are insufficient data from this study to support specific treatment recommendations. When the primary adverse effect is non-apnoeic hypoxaemia, supplemental oxygen appears to be the most appropriate option. In patients who have frequent apnoeas and hypopnoeas, therapy with positive pressure should be considered, especially if there are indications of increased airways resistance or obstructive events. Therapy with adaptive servoventilation appears to be effective in some cases, but the efficacy of this modality remains controversial $[23,45]$. It is advised that patients with mild opioid-induced respiratory abnormalities should be followed clinically.

\section{Summary comments}

Prescriptions of buprenorphine have skyrocketed, presumably fuelled by the perception that this opioid is safe because respiratory suppression is limited by the ceiling effect. Compared to methadone, use of buprenorphine seems to be less likely to result in fatal overdose; however, there have been no systematic studies of the effects of buprenorphine on respiration during sleep until now. Our observations should raise concern about the potential for adverse and possibly lethal respiratory consequences during sleep using ordinary doses of buprenorphine.

\section{Acknowledgements}

Data from this work was presented in abstract form at the American College of Chest Physicians Annual Meeting, October 24, 2011, Honolulu, HI, USA. 


\section{References}

1 Farney RJ, Walker JM, Cloward TV, et al. Sleep-disordered breathing associated with long-term opioid therapy. Chest 2003; 123: 632-639.

2 Walker JM, Farney RJ, Rhondeau SM, et al. Chronic opioid use is a risk factor for the development of central sleep apnea and ataxic breathing. J Clin Sleep Med 2007; 3: 455-461.

3 Teichtahl H, Prodomidis A, Miller B, et al. Sleep-disordered breathing in stable methadone programme patients: a pilot study. Addiction 2001; 96: 395-403.

4 Webster LR, Choi Y, Desai H, et al. Sleep-disordered breathing and chronic opioid therapy. Pain Med 2008; 9: 425-432. Farney RJ, Walker JM. Central sleep apnea due to drug or substance. In: Kushida C, ed. The Encyclopedia of Sleep. Vol. 3. Waltham, MA, Academic Press, 2013; pp. 253-264.

6 Centers for Disease Control and Prevention (CDC). Increase in poisoning deaths caused by non-illicit drugs Utah, 1991-2003. MMWR Morb Mortal Wkly Rep 2005; 54: 33-36.

7 Centers for Disease Control and Prevention (CDC). Vital signs: overdoses of prescription opioid pain relievers United States, 1999-2008. MMWR Morb Mortal Wkly Rep 2011; 60: 1487-1492.

8 Chung F, Yegneswaran B, Liao P, et al. STOP questionnaire: a tool to screen patients for obstructive sleep apnea. Anesthesiology 2008; 108: 812-821.

9 Kuehn BM. Opioid prescriptions soar: increase in legitimate use as well as abuse. JAMA 2007; 297: 249-251.

10 Office of Diversion Control. National Forensic Laboratory Information System (NFLIS). Special Report: Methadone and Buprenorphine, 2003-2008. Washington, US Drug Enforcement Administration, 2009.

11 Walsh SL, Preston KL, Stitzer ML, et al. Clinical pharmacology of buprenorphine: ceiling effects at high doses. Clin Pharmacol Ther 1994; 55: 569-580.

12 Johnson RE, Fudala PJ, Payne R. Buprenorphine: considerations for pain management. J Pain Symptom Manage 2005; 29: 297-326.

13 Kahan M, Srivastava A, Ordean A, et al. Buprenorphine: new treatment of opioid addiction in primary care. Can Fam Physician 2011; 57: 281-289.

14 Dahan A, Yassen A, Romberg R, et al. Buprenorphine induces ceiling in respiratory depression but not in analgesia. Br J Anaesth 2006; 96: 627-632.

15 Dahan A, Yassen A, Bijl H, et al. Comparison of the respiratory effects of intravenous buprenorphine and fentanyl in humans and rats. Br J Anaesth 2005; 94: 825-834.

16 Auriacombe M, Franques P, Tignol J. Deaths attributable to methadone vs buprenorphine in France. JAMA 2001; 285: 45 .

17 Auriacombe M, Fatséas M, Dubernet J, et al. French field experience with buprenorphine. Am J Addict 2004; 13: Suppl. 1, S17-S28.

18 Substance Abuse and Mental Health Services Administration. Buprenorphine Drug Addiction Treatment Act of 2000. http://buprenorphine.samhsa.gov/fulllaw.html Date last accessed: June 9, 2013. Date last updated: 2000.

19 Ladi L, Wang J, Getsy J. Sleep-disordered breathing with buprenorphine-naloxone use: a case report. Chest 2010; 138: 700A.

20 McNicholas L. Clinical Guidelines for the use of Buprenorphine in the Treatment of Opioid Addiction. A Treatment Improvement Protocol. TIP 40. Rockville, US Department of Health and Human Services, 2004.

21 Farney RJ, Walker JM, Cloward TV, et al. Polysomnography in hospitalized patients using a wireless wide area network. J Clin Sleep Med 2006; 2: 28-34.

22 Iber C, Ancoli-Israel S, Chesson A, et al. The AASM Manual for the Scoring of Sleep and Associated Events: Rules, Terminology and Technical Specifications. 1st Edn. Westchester, American Academy of Sleep Medicine, 2007.

23 Farney RJ, Walker JM, Boyle KM, et al. Adaptive servoventilation (ASV) in patients with sleep disordered breathing associated with chronic opioid medications for non-malignant pain. J Clin Sleep Med 2008; 4: 311-319.

24 Breiman L. Random forests. Machine Learning 2001; 45: 5-32.

25 Breiman L. Manual on Setting Up, Using, and Understanding Random Forests V3.1. http://oz.berkeley.edu/users/ breiman/Using_random_forests_V31.pdf Date last accessed: June 10, 2013.

26 Liaw A, Wiener M. Classification and regression by random forest. $R$ News 2002; 2: 18-22.

27 Conover WJ. One-sample Kolmogorov test. Practical Nonparametric Statistics. 1st Edn. New York, John Wiley \& Sons, 1971; pp. 295-301.

28 Conover WJ. Two-sample Smirnov test. Practical Nonparametric Statistics. 1st Edn. New York, John Wiley \& Sons, 1971; pp. 309-314.

29 Farney RJ, Walker BS, Farney RM, et al. The STOP-Bang equivalent model and prediction of severity of obstructive sleep apnea: relation to polysomnographic measurements of the apnea/hypopnea index. J Clin Sleep Med 2011; 7: 459-465.

30 Hukins C. Mallampati class is not useful in the clinical assessment of sleep clinic patients. J Clin Sleep Med 2010; 6: 545-549.

31 Bowman AWA. Applied Smoothing Techniques for Data Analysis. The Kernel Approach with S-Plus Illustrations. NewYork, Oxford University Press, 1997.

32 Benjamini Y, Hochberg Y. Controlling the false discovery rate: a practical and powerful approach to multiple testing. J R Stat Soc Series B Stat Methodol 1995; 57: 289-300.

33 Mégarbane B, Hreiche R, Pirnay S, et al. Does high-dose buprenorphine cause respiratory depression? Possible mechanisms and therapeutic consequences. Toxicol Rev 2006; 25: 79-85.

34 Labby D., Koder M., Amann T. Opioids and Chronic Non-Malignant Pain: A Clinician's Handbook. Portland, CareOregon, 2003.

35 Pattinson KT. Opioids and the control of respiration. Br J Anaesth 2008; 100: 747-758.

36 Pasternak GW. Incomplete cross tolerance and multiple $\mu$-opioid peptide receptors. Trends Pharmacol Sci 2001; 22: $67-70$.

37 Xie GX, Palmer PP. RGS proteins: new players in the field of opioid signaling and tolerance mechanisms. Anesth Analg 2005; 100: 1034-1042.

38 Walsh SL, Eissenberg T. The clinical pharmacology of buprenorphine: extrapolating from the laboratory to the clinic. Drug Alcohol Depend 2003; 70: Suppl. 2, S13-S27. 
39 Walsh SL, Preston KL, Bigelow GE, et al. Acute administration of buprenorphine in humans: partial agonist and blockade effects. J Pharmacol Exp Ther 1995; 274: 361-372.

40 Walsh SL, June HL, Schuh KJ, et al. Effects of buprenorphine and methadone in methadone-maintained subjects. Psychopharmacology (Berl) 1995; 119: 268-276.

41 Kintz P. Deaths involving buprenorphine: a compendium of French cases. Forensic Sci Int 2001; 121: 65-69.

42 Kintz P. A new series of 13 buprenorphine-related deaths. Clin Biochem 2002; 35: 513-516.

43 Boyd J, Randell T, Luurila H, et al. Serious overdoses involving buprenorphine in Helsinki. Acta Anaesthesiol Scand 2003; 47: 1031-1033.

44 Mogri M, Desai H, Webster L, et al. Hypoxemia in patients on chronic opiate therapy with and without sleep apnea. Sleep Breath 2009; 13: 49-57.

45 Javaheri S, Malik A, Smith J, et al. Adaptive pressure support servoventilation: a novel treatment for sleep apnea associated with use of opioids. J Clin Sleep Med 2008; 4: 305-310. 